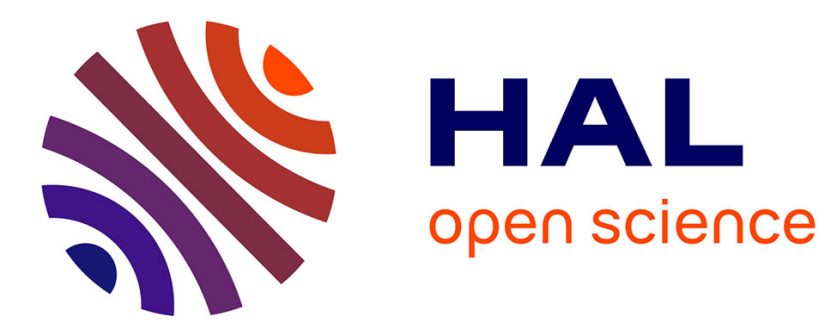

\title{
The hall effect in HMTSeF-TCNQ
}

J.R. Cooper, M. Weger, G. Delplanque, D. Jérome, K. Bechgaard

\section{To cite this version:}

J.R. Cooper, M. Weger, G. Delplanque, D. Jérome, K. Bechgaard. The hall effect in HMTSeF-TCNQ. Journal de Physique Lettres, 1976, 37 (12), pp.349-353. 10.1051/jphyslet:019760037012034900 . jpa00231309

\section{HAL Id: jpa-00231309 https://hal.science/jpa-00231309}

Submitted on 1 Jan 1976

HAL is a multi-disciplinary open access archive for the deposit and dissemination of scientific research documents, whether they are published or not. The documents may come from teaching and research institutions in France or abroad, or from public or private research centers.
L'archive ouverte pluridisciplinaire HAL, est destinée au dépôt et à la diffusion de documents scientifiques de niveau recherche, publiés ou non, émanant des établissements d'enseignement et de recherche français ou étrangers, des laboratoires publics ou privés. 


\title{
THE HALL EFFECT IN HMTSeF-TCNQ (*)
}

\author{
J. R. COOPER $\left({ }^{* *}\right)$, M. WEGER $\left({ }^{* * *}\right)$, G. DELPLANQUE, D. JÉROME
}

Laboratoire de Physique des Solides (****), Université Paris-Sud, 91405 Orsay, France

and

\section{K. BECHGAARD}

\author{
H. C. Oersted Institute, Universitetsparken 5, DK-2100, Copenhague, Denmark
}

(Reçu le 15 juillet 1976, révisé le 14 septembre 1976, accepté le 15 septembre 1976)

\begin{abstract}
Résumé. - Nous avons mesuré l'effet Hall dans le complexe organique de transfert de charge HMTSeF-TCNQ, en fonction de la température et de la pression. La valeur de la constante de Hall indique un comportement métallique au voisinage de la température ambiante et un comportement semi-métallique à basse température avec environ 1 porteur pour $500-1000$ molécules du complexe. La constante de Hall positive (trous) à haute température devient négative (électrons) au voisinage de $32-36 \mathrm{~K}$. Nous avons aussi observé une très forte magnétorésistance anisotrope qui a été mesurée en fonction de la température et de la pression. L'anisotropie de la résistivité a aussi été mesurée en fonction de la température et de la pression et nous avons observé au-dessous de $20 \mathrm{~K}$ une croissance beaucoup plus rapide de la résistance suivant la direction des liaisons $\mathrm{Se}-\mathrm{N}$ que le long de l'axe d'empilement. La mobilité des porteurs sous pression croît jusqu'à $4 \times 10^{4} \mathrm{~cm}^{2} / \mathrm{Vs}$ à basse température. Nous avons pu ainsi confirmer le caractère semi-métallique de ce complexe sous haute pression à basse température. Ce travail représente la première mise en évidence d'un effet Hall dans un métal organique.
\end{abstract}

\begin{abstract}
The Hall effect in the organic charge transfer compound HMTSeF-TCNQ was measured as function of temperature and pressure. The Hall constant indicates metallic behaviour near ambient temperature, and semi-metallic behaviour at low temperatures, with approximately one carrier per 500-1 000 formula units. The Hall constant changes sign around 32-36 K from holelike at high temperatures to electron-like at low ones. The magnetoresistance was also measured as function of temperature and pressure, and found to be very large and anisotropic. The anisotropy in the resistivity was also measured as function of temperature and pressure, and the resistance in the crystalline direction of the $\mathrm{Se}-\mathrm{N}$ bonds rises very rapidly below $20 \mathrm{~K}$, much faster than the resistivity along the stacking axis. The carrier mobility under pressure at low temperature rises to approximately $4 \times 10^{4} \mathrm{~cm}^{2} / \mathrm{Vs}$. Thus the semi-metallic nature of this material at low temperatures, under pressure, has been established and the Hall constant investigated for the first time in an organic metal.
\end{abstract}

We wish to report the observation, for the first time, of the Hall effect in a metallic organic charge transfer complex, HMTSeF-TCNQ (hexa methylene tetra selena fulvalene tetra cyano quino dimethanide) and the determination of the semi-metallic character of this compound by its large Hall constant.

$\left(^{*}\right)$ Work in Orsay supported in part by D.G.R.S.T. Contract no 75-7-0820.

$\left({ }^{* *}\right)$ Currently at the Institute of Physics of the University, P.O.B.304, Zagreb, Yougoslavie.

$\left({ }^{* * *}\right)$ On visit from the Hebrew University, Jerusalem, and Nuclear Research Center, Negev, Israel.

${ }^{(* * * *)}$ Laboratoire associé au C.N.R.S.
HMTSeF-TCNQ possesses rather high conductivities down to liquid helium temperatures [1]. Under hydrostatic pressure in excess of $4 \mathrm{kbar}$, the resistance decreases monotonically with temperature and a large magnetoresistance is present below about $50 \mathrm{~K}$ [2]. A large diamagnetism at low temperatures suggests semi-metallic behaviour [3]. A band structure model was proposed which at low temperatures has very small pockets of electrons and holes, rather asymmetrical in their effective mass [4]. A crucial test of semi-metallic behaviour is a large Hall coefficient.

The Hall constant was measured for current flowing along the high-conductivity (hc) needle axis, and a 
magnetic field applied along the low-conductivity (lc) axis. The Hall voltage was measured along the intermediate-conductivity (ic) axis. The contacts were made by silver paint and two voltage contacts were placed on one side of the crystal, so that the resistive voltage could be zeroed-out for the Hall voltage measurement, as well as monitored to measure the conductivity and magnetoresistance. The dimensions of the samples are given in the caption to figure 1. Particularly long and narrow crystals were chosen to minimise the shorting out of the Hall voltage by the current contacts, which can cause an appreciable

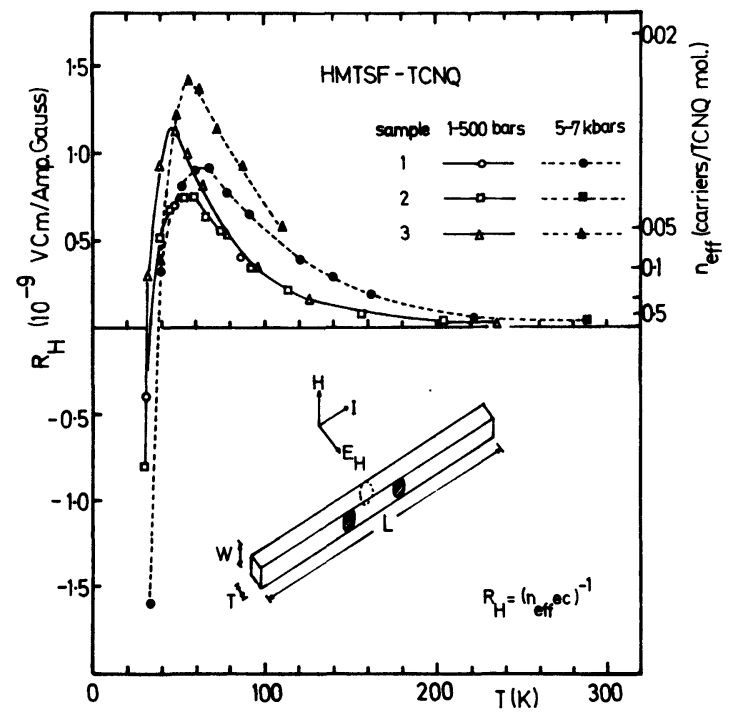

a)

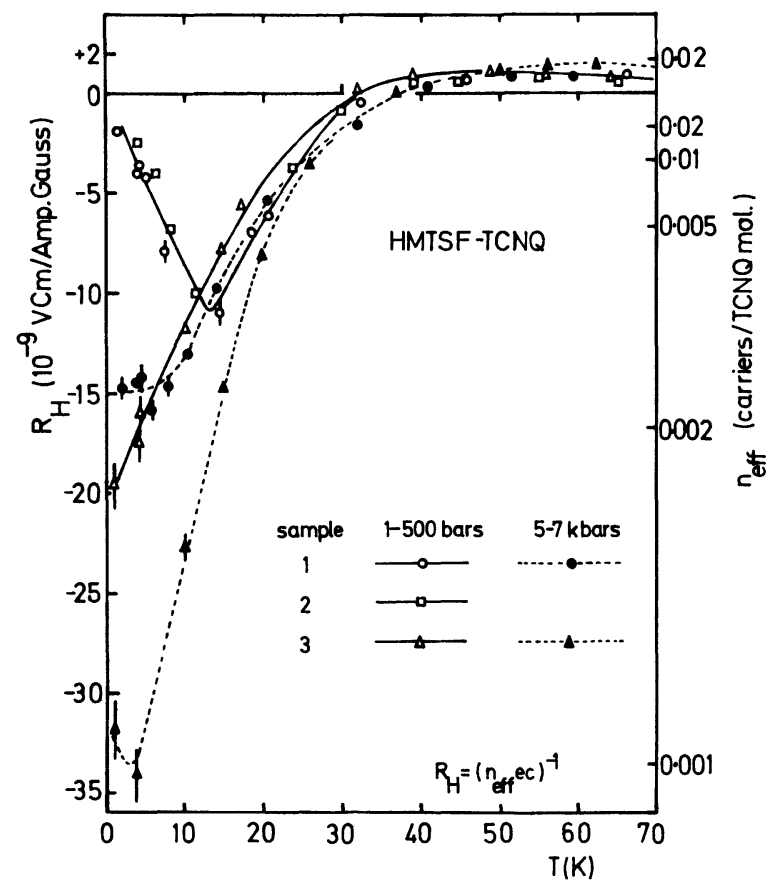

b)

FIG. 1. - The Hall constant as a function of temperature for $P=0$ and $P \simeq 6 \mathrm{kbar}$. The sample dimensions were $L=1.5$, 1.4 and $2.4 \mathrm{~mm}, W=110 \mu \mathrm{m}, 130 \mu \mathrm{m}$ and $100 \mu \mathrm{m}$, and $T=70 \mu \mathrm{m}$, $60 \mu \mathrm{m}$ and $20 \mu \mathrm{m}$ for samples 1,2 and 3 respectively. error in anisotropic materials when the length/ thickness ratio is not large enough [5]. From this point of view sample 3 was the best, it was $2.4 \mathrm{~mm}$ long and $20 \mu \mathrm{m}$ thick.

The Hall voltage was measured for fields applied in both directions to avoid errors due to magnetoresistive voltages. Both alternating $(70 \mathrm{~Hz})$ and direct currents in the range $50-200 \mu \mathrm{A}$ were used, and Hall voltagés up to several $\mu \mathrm{V}$ were observed at $20 \mathrm{kOe}$.

The Hall voltage was measured as function of temperature, between 1.5 and $200 \mathrm{~K}$ as function of pressure, for hydrostatic pressures up to $6 \mathrm{kbar}$, and as function of magnetic field up to $21 \mathrm{kOe}$.

In figure 1 we show the Hall constant as function of temperature, for $P=0$ and $P=5 \mathrm{kbar}$. The Hall constant is defined as $j^{-1} \mathrm{~d} E / \mathrm{d} H$ as $H \rightarrow 0$. The Hall constant is seen to be small and hole-like at high temperatures, to rise as the temperature is lowered, to pass through zero at about $32-36 \mathrm{~K}$ and to become large and electron-like below this temperature. Hydrostatic pressure has only a small effect. The two samples with a smaller length/thickness ratio (samples 1 and 2) gave an apparent decreasing Hall voltage at helium temperatures and $P=0$, probably due to the large anisotropy in the conductivity there [5].

At low temperatures, the Hall voltage is not a

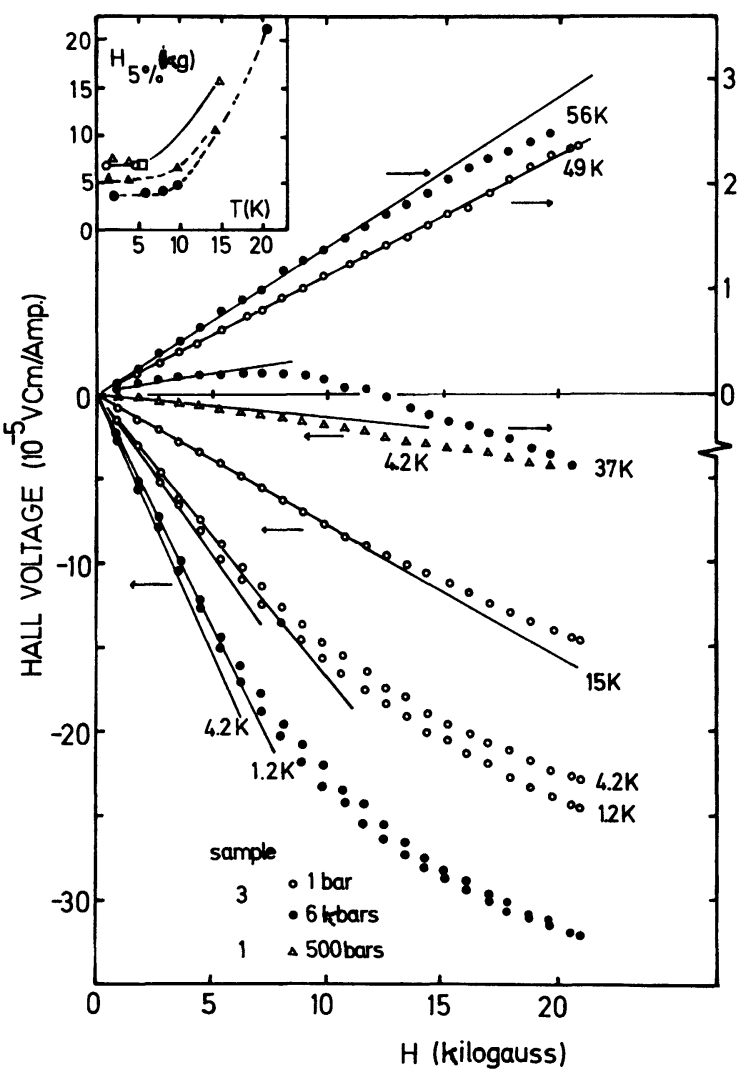

FIG. 2. - The Hall voltage as a function of magnetic field at several temperatures for $P=0$ and $P \simeq 6 \mathrm{kbar}$. Inset : Magnetic field at which the Hall Voltage shows $5 \%$ deviations from linearity, for the three samples with the same symbols as in figure 1 . 

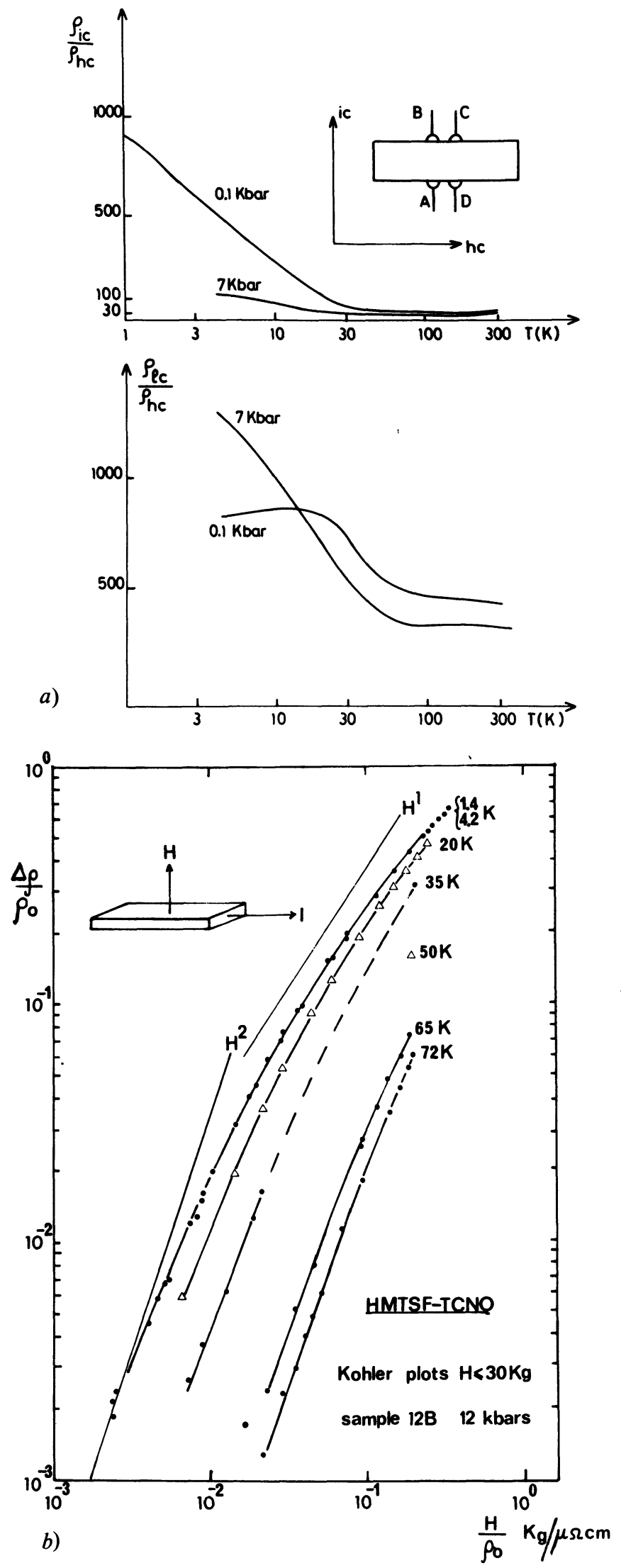

FIG. 3. - (a) Anisotropy in electrical resistivity $\rho_{\text {ic }} / \rho_{\text {hc }}$ and $\rho_{\mathrm{lc}} / \rho_{\mathrm{hc}}$ as a function of temperature and pressure. The average value of $\rho_{\mathrm{ic}} / \rho_{\mathrm{hc}}$ at ambient temperature and pressure was $33 \pm 13$ for three samples. (b) Magnetoresistance under pressure for fields in the ic direction presented in the form of Kohler plots (ln $\Delta \rho / \rho_{0}$ vs. $\left.\ln H / \rho_{0}\right)$ at different temperatures. linear function of the magnetic field. At $38 \mathrm{~K}$, near where the Hall constant changes sign with decreasing temperature, it also changes sign with increasing magnetic field (Fig. 2). At helium temperatures, the Hall constant decreases with increasing field (Fig. 2). The magnetic field at which the Hall voltage becomes non-linear with the field, decreases with decreasing temperature, as shown in the inset of figure 2 .

The Hall constant at high field (about $20 \mathrm{kOe}$ ) is somewhat less pressure dependent than the $H \rightarrow 0$ limit.

The anisotropy in resistance is shown in figure $3 a$. It was measured following the method of Van der Pauw [6]. At ambiant temperature and pressure the value of $\rho_{\mathrm{ic}} \cdot \rho_{\mathrm{hc}}$ is very reproducible, however, there is some uncertainty in the value of $\rho_{\mathrm{hc}}$. Therefore, the uncertainty in $\rho_{\mathrm{ic}} / \rho_{\mathrm{hc}}$ is somewhat large (about $30 \%$ ). Notice in particular the sharp rise in $\rho_{\mathrm{ic}} / \rho_{\mathrm{hc}}$ below $20 \mathrm{~K}$ at $P=0$, from a value of about 30 at ambient, to a value of approximately 1000 . Thus, the transition of $20 \mathrm{~K}$ affects $\rho_{\text {ic }}$ much more than it affects $\rho_{\text {hc }} \cdot \rho_{\text {lc }} / \rho_{\text {hc }}$ does not show significant anomalies.

A typical example of the magnetoresistance is shown in figure $3 b$. The magnetoresistance is presented in the form of Kohler plots, $\left(\ln \Delta \rho(H) / \rho_{0}\right.$ plotted vs.ln $\left.H / \rho_{0}\right)$, which show the $H^{2}$ dependence at low fields and the linear dependence on $H$ at high fields. For a magnetic field in the lc direction, the magnetoresistance is about 1.8 times larger than for a field in the ic direction. For a field in the he direction, the magnetoresistance is at least one order of magnitude smaller, and the small effect observed could be due to misalignment. This is in contrast with the small, but isotropic, magnetoresistance in TTFTCNQ [7].

For $T<10 \mathrm{~K}, P=0$, the increase in magnetoresistance may be due to a Corbino effect, caused by the increasing anisotropy (shorting of the Hall voltage by the current contacts). There is no anomaly at the temperature where the Hall voltage vanishes. Thus, the Corbino effect is small at other temperatures and under pressure.

Discussion. - A large Hall constant at low temperatures can be explained in one of two ways : (a) We have a semi-metal with equal number of electrons and holes, but the electrons and holes have rather different effective masses and/or collision times. For this case, $R_{\mathrm{H}}=(1 / n e c)\left(\mu_{\mathrm{h}}-\mu_{\mathrm{e}}\right) /\left(\mu_{\mathrm{h}}+\mu_{\mathrm{e}}\right)$ [5]. (b) We have an extrinsic semiconductor, probably with conduction due to a degenerate impurity band. In this case, we would expect different Hall constants and different resistivities, for different batches of crystals, grown under rather different conditions of purity, temperature, etc. This is in contrast with experiment, the resistivity and Hall constant being very nearly the same for quite a number of samples, from different batches. The data at $P=0, T<20 \mathrm{~K}$, 
are an exception, and for them there are appreciable differences between different samples. For this reason, we favour $(a)$.

The semi-metallic interpretation is also in accord with several other properties of this material, namely : (i) At low temperatures $(T<30 \mathrm{~K})$, the susceptibility is diamagnetic [3] $\left(\chi=-2 \times 10^{-4} \mathrm{emu} / \mathrm{mol}\right.$ when the zero is defined as the sum of the susceptibilities of separated HMTSeF and TCNQ). This diamagnetism is interpreted as a Landau-Peierls orbital diamagnetism, associated with very small cross-sectional areas of the Fermi surface. (ii) The resistivity $\rho$ (under pressure) at very low temperature $(T<2 \mathrm{~K})$ is given by $\rho=A+B T^{2}$ [2]. This $T^{2}$ law is characteristic of semi-metals. (iii) The theoretical band model [4] indicates electron and hole Fermi surfaces of a very small volume, therefore a very small number of free carriers. The volumes of the electron and hole Fermi surfaces predicted is in excellent agreement with the value of carrier concentration-found here.

The standard formulas

$$
\begin{gathered}
\sigma=n|e|\left(\mu_{\mathrm{h}}+\mu_{\mathrm{e}}\right), \quad R_{\mathrm{H}}=\frac{1}{n|e| c} \frac{\mu_{\mathrm{h}}-\mu_{\mathrm{e}}}{\mu_{\mathrm{h}}+\mu_{\mathrm{e}}} \\
\Delta \rho / \rho H^{2}=\mu_{\mathrm{h}} \mu_{\mathrm{e}} / c^{2}
\end{gathered}
$$

yield : $n=1.2 \times 10^{18}$ carriers $/ \mathrm{cm}^{3}$;

$\mu_{\mathrm{e}}=4 \times 10^{4} \mathrm{~cm}^{2} / \mathrm{Vs}, \quad \mu_{\mathrm{h}}=1.2 \times 10^{4} \mathrm{~cm}^{2} / \mathrm{Vs}$ at $4 \mathrm{~K}$.

However, these formulas do not apply to anisotropic bands. For an anisotropic collision time,

$$
R_{\mathrm{H}}=\frac{1}{n e c} \frac{\left\langle\tau^{2}\right\rangle}{\langle\tau\rangle^{2}}
$$

and for anisotropic effective masses, there is a correction too. For a planar Fermi surface $R_{\mathrm{H}} \simeq 2 /$ nec; at low temperatures, the FS is in the form of thin discs perpendicular to the he axis, so perhaps the expression for a planar FS may apply, and the above value of $n$ may be low by a factor of two or so.

The sign of the Hall constant above $36 \mathrm{~K}$, corresponding to holes, is in agreement with the sign of the thermoelectric effect [1]. The small Hall constant at temperatures approaching ambient, is in accord with the metallic FS there [4]. According to that model, at high temperatures TCNQ carriers are electron-like and HMTSeF carriers are hole-like, thus a larger mobility of the HMTSeF electrons may account for the sign of the Hall constant there. At low temperatures, the sign of the high-mobility carriers depends on the position of the nearest excited molecular states; states below $E_{\mathrm{F}}$ (excited states for holes) yield high mobility electrons, and states above $E_{\mathrm{F}}$ yield high mobility holes [4].

The change in resistivity, $\Delta \rho(H)$ due to the magnetic field is not strongly pressure dependent, though the resistivity $\rho$ is. Also thermal and pressure cycling affects $\rho_{0}$ more than $\Delta \rho(H)$. Thus, we can think of, at least, two possible alternatives to explain these features.

i) The number of carriers at very low temperature increases under pressure as a consequence of the removal of the metal-insulator transition by pressure in excess of $4 \mathrm{kbar}$. Refering to the experimental results on figure 1, a naive interpretation would rather suggest a decrease of $n$ under pressure. However, some change in the carrier mobilities accompanying the modification of the Fermi surface under pressure could account for the larger Hall constant observed at high pressure.

ii) Lèt us define

$$
\rho^{1}(T)=\rho(T, P=0)-\rho(T, P=10 \mathrm{kbar}) .
$$

Then, this extra zero-pressure resistivity rises fast as the temperature is lowered below $20 \mathrm{~K}$ [2]. Perhaps we can account for $\rho^{1}$ as due to extra scattering (rather than a smaller number of carriers). In that case, this extra scattering, and the scattering caused by the magnetic field, appear to be additive from the experimental data. Perhaps this extra scattering is due to some disorder that builds up below $20 \mathrm{~K}$, due to some Jahn-Teller effect, which is suppressed by hydrostatic pressure.

The Peierls transition is also a special case of a Jahn-Teller distortion, but we have no evidence that it indeed occurs here. The large increase in $\rho_{\text {ic }}$ is different from what is observed in TTF-TCNQ [8]. Note that the direction ic is the direction of the N-Se bonds, which are particularly strong in HMTSeFTCNQ [4, 9]. A metal-to-insulator transition of this component of the resistivity, may perhaps be due to a Jahn-Teller effect involving these bonds (for example, bond lengths becoming unequal). Part of the sample-dependent increase in apparent $\rho_{\mathrm{hc}}$ below $20 \mathrm{~K}$ and $P=0$ may be due to the large increase in $\rho_{\text {ic }}$.

While there are to our knowledge no reported data on the Hall effect in charge transfer metals, the Hall constant in the semiconductor TEA-TCNQ 2 at ambient temperature has been reported [10]. It is $R_{\mathrm{H}}=2 \times 10^{-9} \mathrm{~V} \mathrm{~cm} / \mathrm{AG}$, about two orders larger than we find in HMTSeF-TCNQ near ambient temperatures (it is still an order smaller than the value we find at helium temperatures), and this value is in accord with the semiconducting nature of this compound.

In conclusion, whatever the mechanism of the metal-to-insulator transition at $P=0$ is, the existence of a very large Hall effect at low temperature, and a low one at ambient, is a striking confirmation of the semi-metallic behaviour of HMTSeF-TCNQ at low temperature under pressure, and its metallic nature at ambient. 
Acknowledgments. - We benefited greatly from discussions with professors J. Friedel, J. Bok, and P. Pincus, and Dr. G. Soda. One of us (J.R.C.) wishes to thank Dr. A. Janozcy and J. P. Farges for stimulating discussions, and Dr. A. Landesman at Orme des Merisiers for making his stay at Orsay possible. This work could not have been carried out without the constant assistance of $\mathrm{G}$. Malfait in operating the high-pressure equipment. We wish to thank Dr. Fert for providing a Hall standard and for valuable discussions.
Note Added in Proof. - After this paper was submitted, it was brought to our attention that N. P. Ong, A. M. Portis, and K. K. Kanazawa already measured the Hall constant of TTF-TCNQ at ambient temperature [Bull. APS 20 (1975) 465] by microwave techniques. More recent work by these authors (private communication) yields values of $3 \times 10^{-2}$ to $8 \times 10^{-2} \mathrm{~cm}^{2} / \mathrm{Vs}$ for the Hall mobility. This gives a Hall constant roughly within a factor of 3 of the value expected for the given charge transfer ( 0.55 electron/ molecule) with $\mu_{\mathrm{e}} \ll \mu_{\mathrm{h}}$, similar to the present data on HMTSeF-TCNQ (Fig. 1a) at ambient temperature.

\section{References}

[1] Bloch, A. N., Cowan, D. O., Bechgaard, K., Pyle, R. E., Banks, R. H., Poehler, T. O., Phys. Rev. Lett. 34 (1975) 1561.

[2] Cooper, J. R., Weger, M., Jérome, D., Lefur, D., BechGAARD, K., Cowan, D. O., Bloch, A. N., Solid State Commun. 19 (1976) 749.

[3] Soda, G., Jérome, D., Weger, M., Bechgaard, K., PederSEN, E., Solid State Commun. (in press).

[4] Weger, M., Solid State Commun. 19 (1976) 1149.
[5] BEER, A. C., Galvanomagnetic Effects in Semiconductors (Academic Press, New York) 1963.

[6] VAn der Pauw, L. J., Philips Res. Repts. 13 (1958) 1.

[7] Tiedje, T., Carolan, J. F., Berlinsky, A. J., Weiler, C., Can. J. Phys. 53 (1975) 1593.

[8] Coleman, L. B., Thesis, Univ. of Pennsylvania (1975).

[9] Phillips, T. E., Kistenmacher, T. J., Bloch, A. N., Cowan, D. O., J.C.S. Chem. Commun. (1976) 334.

[10] Farges, J. P., Bran, A., Vasilesca, D., Dupuis, P., Néel, J., Phys. Stat. Sol. 37 (1970) 745. 